Pacific Journal of Mathematics

DUALS OF LORENTZ SPACES 


\title{
DUALS OF LORENTZ SPACES
}

\author{
G. D. AlLEN
}

An explicit representation of the duals of Lorentz sequence spaces having "regular" weights is provided.

1. Introduction. Lorentz spaces are rearrangement-invariant weighted $l_{p}$ spaces, and as such it is necessary to consider only the positive cone of positive sequences in their study. Indeed it is necessary to consider only the sub-cone of positive decreasing sequences.

If $X$ is a sequence space, denote by $X^{+}$the subset of $X$ of nonnegative sequences, and by $X^{++}$the subset of $X^{+}$of decreasing sequences (e.g., $\left.l_{p}, l_{p}^{+}, l_{p}^{++}\right)$. For any infinite sequence $\left\{\mu_{n}\right\}$ converging to zero, define $\left\{\hat{\mu}_{n}\right\}$ to be the decreasing rearrangement of $\left\{\left|\mu_{n}\right|\right\}$. As is common, $c_{\mathrm{n}}$ denotes the set of infinite sequences with limit 0 .

Let $\left\{\pi_{n}\right\} \in c_{0}^{++} \mid l_{1}^{+}$. For any $1 \leqq p<\infty$ define $d(\pi, p)$ to be the set of all sequences $\left\{\mu_{n}\right\}$ such that

$$
\sum \pi_{n}\left(\hat{\mu}_{n}\right)^{p}<\infty .
$$

The norm on $d(\pi, p)$ is $\left(\sum \pi_{n}\left(\hat{\mu}_{n}\right)^{p}\right)^{1 / p}$, and $d(\pi, p)$ is called a Lorentz space. The duals of the Lorentz spaces $d(\pi, p)$ are denoted by $d^{*}(\pi, p)$. These are rearrangement-invariant Banach spaces and hence if one can characterize $d^{*}(\pi, p)^{++}$all of $d^{*}(\pi, p)$ is characterized.

For $1<p<\infty$, Garling [3] has characterized the duals $d^{*}(\pi, p)$ as follows: $\left\{\alpha_{n}\right\} \in d^{*}(\pi, p)^{++}$if and only if there is a sequence $\left\{\eta_{n}\right\} \in$ $l_{q}^{++}((1 / p+1 / q)=1)$ such that

$$
\sup _{n} \frac{\sum_{j=1}^{n} \alpha_{j}}{\sum_{j=1}^{n} \eta_{j} \pi_{j}^{1 / p}}<\infty .
$$

In the case $p=1,\left\{\alpha_{n}\right\} \in d^{*}(\pi, 1)^{++}$if and only if

$$
\sup _{n} \frac{\sum_{j=1}^{n} \alpha_{j}}{\sum_{j=1}^{n} \pi_{j}}<\infty .
$$

We intend to show that these duals have a particularly simple structure for a broad class of sequences $\left\{\pi_{n}\right\}$. Namely; the sequence $\left\{\pi_{n}\right\} \in c_{0}^{++}$is said to be regular if

$$
\sum_{j=1}^{n} \pi_{j}=0\left(n \pi_{n}\right)
$$


For example, the sequences $\left\{n^{-p}\right\}, 0<p<1$, and $\left\{(\log n)^{-p}\right\}, p>0$, are regular but the sequence $\left\{n^{-1}\right\}$ is not. The concept of regular sequences was first used by Gohberg and Krein [4], and was also used by Altshuler [2] to give necessary and sufficient conditions that the Lorent spaces $d(\pi, p), p>1$, are uniformly convexifiable.

A necessary and sufficient condition that a sequence $\left\{\pi_{n}\right\} \in c_{0}^{++}$be regular is that

$$
\inf _{n} \frac{\sum_{j=1}^{k n} \pi_{j}}{\sum_{j=1}^{n} \pi_{j}} \geqq c>1
$$

for some (and hence all) integers $k \geqq 2$ (cf. Allen and Shen [1]).

2. Main Result. Our main result is stated as follows.

THEOREM 1. If $\left\{\pi_{n}\right\}$ is regular, then for $p>1, p^{-1}+q^{-1}=1$,

$$
\left\{\alpha_{n}\right\} \in d^{*}(\pi, p) \text { if and only if }\left\{\hat{\alpha}_{n} / \pi_{n}^{1 / p}\right\} \in l^{q} \text {. }
$$

Note that Theorem 1 is the complete generalization of the result (Allen and Shen [1]):

$$
d^{*}(\pi, 1)=\left\{\left\{\xi_{n}\right\} \mid \hat{\xi}_{n}=0\left(\pi_{n}\right)\right\} \text { if and only if }\left\{\pi_{n}\right\} \text { is regular. }
$$

The proof of Theorem 1 proceeds in a series of lemmas.

Lemma 1. Let $\left\{\alpha_{n}\right\} \in c_{0}^{++}$. If, for some positive integer $k \geqq 2$ the $\sup _{j} \alpha_{j} / \alpha_{k j}=c<k$, then $\left\{\alpha_{j}\right\}$ is regular and

$$
\inf _{n} \sum_{j=1}^{k n} \alpha_{j} / \sum_{j=1}^{n} \alpha_{j} \geqq k / c
$$

Proof. This result follows from (4) since

$$
\sum_{j=1}^{k n} \alpha_{j} \geqq \sum_{j=1}^{n} k \alpha_{k j} \geqq k / c \sum_{j=1}^{n} \alpha_{j}
$$

Lemma 2. Let $\left\{\eta_{j}\right\} \in l_{q}^{++}, q>1$, and $\left\{\eta_{j}\right\} \notin l_{r}$ for all $r<q$. Then there is a regular sequence $\left\{\xi_{j}\right\} \in l_{q}^{++}$for which $\eta_{j} \leqq \xi_{j}, j=1,2, \cdots$. Moreover for any $\varepsilon>0$ the sequence $\left\{\xi_{j}\right\}$ may be chosen so that

$$
\inf _{n} \sum_{j=1}^{2 n} \xi_{j} / \sum_{j=1}^{n} \xi_{j}>2^{(q-1) / q}-\varepsilon .
$$

Proof. For $1<q_{1}<q,\left\{\eta_{j}^{q_{1}}\right\} \in l_{q / q_{1}}$. Define $\left\{\xi_{n}\right\}$ by 


$$
\xi_{n}=\left(\frac{1}{n} \sum_{j=1}^{n} \eta_{j}^{q_{1}}\right)^{1 / q_{1}}
$$

Then

$$
\xi_{n}^{q_{1}} / \xi_{2 n}^{q_{1}}=2 \sum_{j=1}^{n} \eta_{j}^{q_{1}} / \sum_{j=1}^{2 n} \eta_{j}^{q_{1}}<2
$$

By Hardy's inequality $\left\{\xi_{j}^{q_{1}}\right\} \in l_{q \mid q_{1}}^{++}$; so $\left\{\xi_{j}\right\} \in l_{q}^{++}$. By Lemma $1\left\{\xi_{n}\right\}$ is regular, from above $\xi_{j} / \xi_{2 j}<2^{1 / q_{1}}$, and from (6)

$$
\sum_{j=1}^{2 n} \xi_{j} / \sum_{j=1}^{n} \xi_{j}>2^{\left(q_{1}-1\right) / q_{1}}>2^{(q-1) / q}-\varepsilon,
$$

for any $\varepsilon>0$ if $q_{1}$ is sufficiently close to $q$.

LEMMA 3. Let $\left\{\pi_{n}\right\}$ be a regular sequence and let $p>1$. Define $\left\{\pi_{n}^{*}\right\}$ by $\pi_{n}^{*}=(1 / n) \sum_{j=1}^{n} \pi_{j}$. Then

$$
\inf _{n} \sum_{j=1}^{2 n}\left(\pi_{j}^{*}\right)^{1 / p} / \sum_{j=1}^{n}\left(\pi_{j}^{*}\right)^{1 / p}>2^{(p-1) / p} .
$$

Proof. From the regularity of $\left\{\pi_{j}\right\}$ it follows that

$$
\sum_{j=1}^{2 n} \pi_{j} / \sum_{j=1}^{n} \pi_{j} \geqq k_{1}>1
$$

Thus $\pi_{2 n}^{*} / \pi_{n}^{*}>k_{1} / 2$, and $\left(\pi_{n}^{*} / \pi_{2 n}^{*}\right)^{1 / p}<\left(2 / k_{1}\right)^{1 / p}$. By Lemma 1

$$
\inf _{n} \sum_{j=1}^{2 n}\left(\pi_{j}^{*}\right)^{1 / p} / \sum_{j=1}^{n}\left(\pi_{j}^{*}\right)^{1 / p}>2 /\left(2 / k_{1}\right)^{1 / p}=2^{(p-1) / p} k_{1}^{1 / p} .
$$

Call two sequences $\left\{\alpha_{n}\right\}$ and $\left\{\beta_{n}\right\} \in c_{0}^{++}$equivalent if

$$
0<\inf \alpha_{n} / \beta_{n} \leqq \sup \alpha_{n} / \beta_{n}<\infty \text {, }
$$

and denote equivalence by $\left\{\alpha_{n}\right\} \sim\left\{\beta_{n}\right\}$.

LEMMA 4. If $\left\{\alpha_{n}\right\}$ and $\left\{\beta_{n}\right\} \in c_{0}^{++}$are equivalent and if $\left\{\alpha_{n}\right\}$ is regular, then $\left\{\beta_{n}\right\}$ is regular.

The proof is a simple application of the definitions. A useful application of Lemma 4 is the following

COROLLARY. Let $\left\{\pi_{n}\right\}$ and $\left\{\lambda_{n}\right\}$ be regular sequences, for which

$$
\inf _{n} \sum_{j=1}^{2 n} \pi_{j} / \sum_{j=1}^{n} \pi_{j} \geqq k_{1}>1 \quad \text { and } \quad \inf _{n} \sum_{j=1}^{2 n} \lambda_{j} / \sum_{j=1}^{n} \lambda_{j} \geqq k_{2}>1 \text {. }
$$

If $k_{1} k_{2}>2$, then $\left\{\pi_{n} \lambda_{n}\right\}$ is regular. 
Proof. Define $\lambda_{n}^{*}=(1 / n) \sum_{j=1}^{n} \lambda_{j}$. Summing by parts,

$$
\begin{aligned}
\sum_{j=1}^{2 n} \pi_{j} \lambda_{j}^{*}= & \sum_{j=1}^{2 n-1}\left(\sum_{i=1}^{j} \pi_{i}\right)\left(\lambda_{j}^{*}-\lambda_{j+1}^{*}\right)+\left(\sum_{i=1}^{2 n} \pi_{i}\right) \lambda_{2 n}^{*} \\
\geqq & \sum_{j=1}^{n-1}\left\{\left(\sum_{i=1}^{2 j} \pi_{i}\right)\left(\lambda_{2 j}^{*}-\lambda_{2 j+1}^{*}\right)+\left(\sum_{i=1}^{2 j+1} \pi_{i}\right)\left(\lambda_{2 j+1}^{*}-\lambda_{2 j+2}^{*}\right)\right\} \\
& +\left(\sum_{i=1}^{2 n} \pi_{i}\right) \lambda_{2 n}^{*} \\
\geqq & k_{1}\left(\sum_{j=1}^{n-1}\left(\sum_{i=1}^{j} \pi_{i}\right)\left(\lambda_{2 j}^{*}-\lambda_{2 j+2}^{*}\right)+\left(\sum_{i=1}^{n} \pi_{i}\right) \lambda_{2 n}^{*}\right) \\
\geqq & k_{1} k_{2} / 2\left(\sum_{j=1}^{n} \pi_{j} \lambda_{j}^{*}\right) .
\end{aligned}
$$

Thus $\left\{\pi_{j} \lambda_{j}^{*}\right\}$ is regular, and so, by Lemma 4 is $\left\{\pi_{j} \lambda_{j}\right\}$.

Proof of Theorem 1. Suppose that $\left\{\alpha_{j}\right\} \in d^{*}(\pi, p)^{++}$. Select $\left\{\eta_{j}\right\}$ satisfying (1) to additionally satisfy $\left\{\eta_{j}\right\} \notin l_{r}$ for all $r<q$. By Lemma 2 we can assume by taking $\left\{\eta_{j}\right\}$ larger if necessary that $\left\{\eta_{j}\right\}$ is regular and

$$
\inf _{n} \sum_{j=1}^{2 n} \eta_{j} \sum_{j=1}^{n} \eta_{j}>2^{(q-1) / q}-\varepsilon
$$

for any fixed $\varepsilon>0$. It is apparent that $d(\pi, p)$ is isomorphic to $d\left(\pi^{*}, p\right)$ where $\left\{\pi_{n}^{*}\right\}$ is the sequence defined by $\pi_{n}^{*}=\sum_{s^{n}=1}^{n} \pi_{j} / n$. Hence $d^{*}(\pi, p)$ and $d^{*}\left(\pi^{*}, p\right)$ are isomorphic. By Lemma 3 and (7) we can assume that $\left\{\pi_{j}^{1 / p}\right\}$ and $\left\{\eta_{j}\right\}$ satisfy the hypotheses of the corollary. Thus by (6) $\alpha_{j}=0\left(\eta_{j} \pi_{j}^{1 / p}\right)$. Writing $\alpha_{j}=\xi_{j} \pi_{j}^{1 / p}$ it follows that $\xi_{j}=$ $0\left(\eta_{j}\right)$, and thus $\left\{\xi_{j}\right\} \in l_{q}$. This proves, together with our earlier remarks, that $d^{*}(\pi, p) \subset l_{q} \cdot d^{*}\left(\pi^{1 / p}, 1\right)$. The reverse inclusion is immediate. The converse of the theorem follows by taking for $\left\{\eta_{j}\right\}$ the decreasing rearrangement of $\left\{\left|\alpha_{j} / \pi_{j}^{1 / p}\right|\right\}$.

3. REMARKS. It could be said that the most important aspect of Theorem 1 is that it provides an explicit representation of the duals of Lorentz spaces with regular weights. We also remark that the function analogue of regularity includes all "weights" currently used in classical interpolation theory. Whether or not Theorem 1 remains true for Lorentz function spaces remains unknown.

\section{REFERENCES}

1. G. D. Allen and L. C. Shen, On the structure of principal ideals of operators, Trans. Amer. Math. Soc., to appear.

2. Z. Altshuler, Uniform convexity in Lorentz sequence spaces, Israel J. Math., 20 (1975), 260-274. 
3. D. J. H. Garling, A class of reflexive symmetric BK-spaces, Canad. J. Math., 21 (1969), 602-608.

4. I. C. Gohberg and M. G. Krein, Introduction to the Theory of Nonselfadjoint Operators in Hilbert Space, English transl. Monographs, Vol. 18, Amer. Math. Soc., Providence, R. I., 1969.

Received July 27, 1977 and in revised form November 10, 1977.

Texas A \& M University

College Station, TX 77843 



\title{
PACIFIC JOURNAL OF MATHEMATICS
}

\section{EDITORS}

RICHARD ARENS (Managing Editor)

University of California

Los Angeles, CA 90024

Charles W. Curtis

University of Oregon

Eugene, OR 97403

C. C. MOORE

University of California

Berkeley, CA 94720
J. DUGUNDJI

Department of Mathematics

University of Southern California

Los Angeles, CA 90007

R. Finn and J. Milgram

Stanford University

Stanford, CA 94305

\section{ASSOCIATE EDITORS}
E. F. BECKENBACH
B. H. Neumann
F. WOLF
K. YosHidA

\section{SUPPORTING INSTITUTIONS}

\author{
UNIVERSITY OF BRITISH COLUMBIA \\ CALIFORNIA INSTITUTE OF TECHNOLOGY \\ UNIVERSITY OF CALIFORNIA \\ MONTANA STATE UNIVERSITY \\ UNIVERSITY OF NEVADA, RENO \\ NEW MEXICO STATE UNIVERSITY \\ OREGON STATE UNIVERSITY \\ UNIVERSITY OF OREGON
}

\author{
UNIVERSITY OF SOUTHERN CALIFORNIA \\ STANFORD UNIVERSITY \\ UNIVERSITY OF HAWAII \\ UNIVERSITY OF TOKYO \\ UNIVERSITY OF UTAH \\ WASHINGTON STATE UNIVERSITY \\ UNIVERSITY OF WASHINGTON
}

The Supporting Institutions listed above contribute to the cost of publication of this Journal, but they are not owners or publishers and have no responsibility for its content or policies.

Mathematical papers intended for publication in the Pacific Journal of Mathematics should be in typed form or offset-reproduced, (not dittoed), double spaced with large margins. Please do not use built up fractions in the text of the manuscript. However, you may use them in the displayed equations. Underline Greek letters in red, German in green, and script in blue. The first paragraph or two must be capable of being used separately as a synopsis of the entire paper. Items of the bibliography should not be cited there unless absolutely necessary, in which case they must be identified by author and journal, rather than by item number. Manuscripts, in triplicate, may be sent to any one of the editors. Please classify according to the scheme of Math. Reviews, Index to Vol. 39. All other communications should be addressed to the managing editor, or Elaine Barth, University of California, Los Angeles, California, 90024.

50 reprints to each author are provided free for each article, only if page charges have been substantially paid. Additional copies may be obtained at cost in multiples of 50 .

The Pacific Journal of Mathematics is issued monthly as of January 1966. Regular subscription rate: $\$ 72.00$ a year (6 Vols., 12 issues). Special rate: $\$ 36.00$ a year to individual members of supporting institutions.

Subscriptions, orders for numbers issued in the last three calendar years, and changes of address should be sent to Pacific Journal of Mathematics, P.O. Box 969, Carmel Valley, CA 93924, U.S.A. Older back numbers obtainable from Kraus Periodicals Co., Route 100, Millwood, NY 10546.

PUBLISHED BY PACIFIC JOURNAL OF MATHEMATICS, A NON-PROFIT CORPORATION

Printed at Kokusai Bunken Insatsusha (International Academic Printing Co., Ltd.). 8-8, 3-chome, Takadanobaba, Shinjuku-ku, Tokyo 160, Japan.

Copyright (C) 1978 by Pacific Journal of Mathematics Manufactured and first issued in Japan 


\section{Pacific Journal of Mathematics}

Vol. 77, No. $2 \quad$ February, 1978

Graham Donald Allen, Duals of Lorentz spaces ................... 287

Gert Einar Torsten Almkvist, The number of nonfree components in the decomposition of symmetric powers in characteristic p .......... 293

John J. Buoni and Bhushan L. Wadhwa, On joint numerical ranges ...... 303

Joseph Eugene Collison, Central moments for arithmetic functions . . . . . . 307

Michael Walter Davis, Smooth G-manifolds as collections of fiber

bundles ........................................ 315

Michael E. Detlefsen, Symmetric sublattices of a Noether lattice......... 365

David Downing, Surjectivity results for $\phi$-accretive set-valued

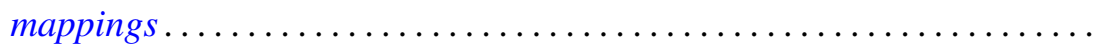

David Allyn Drake and Dieter Jungnickel, Klingenberg structures and partial designs. II. Regularity and uniformity ................. 389

Edward George Effros and Jonathan Rosenberg, $C^{*}$-algebras with approximately inner flip .......................... 417

Burton I. Fein, Minimal splitting fields for group representations. II. . . . . 445

Benjamin Rigler Halpern, A general coincidence theory ............. 451

Masamitsu Mori, A vanishing theorem for the mod $p$ Massey-Peterson spectral sequence ................................ 473

John C. Oxtoby and Vidhu S. Prasad, Homeomorphic measures in the

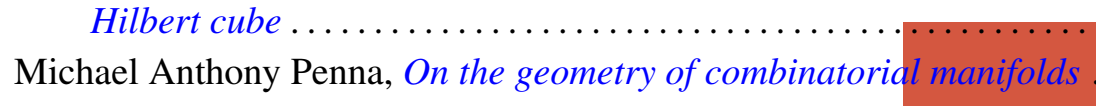

Robert Ralph Phelps, Gaussian null sets and differentiability of Lipschitz map on Banach spaces........................

Herbert Silverman, Evelyn Marie Silvia and D. N. Telage, Locally univalent functions and coefficient distortions...

Donald Curtis Taylor, The strong bidual of $\Gamma(K)$

Willie Taylor, On the oscillatory and asymptotic behavior of solutions of fifth order selfadjoint differential equations ...........

Fu-Chien Tzung, Sufficient conditions for the set of Hausdorff compactifications to be a lattice. 